DOI: $10.4274 /$ tpa.46.77

\title{
Çocuk yoğun bakım biriminde santral venöz kateterizasyon komplikasyonlarının değerlendirilmesi
}

\section{The evaluation of central venous catheterization complications in a pediatric intensive care unit}

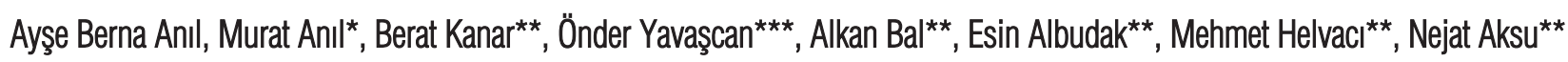 \\ T.C.S.B. Izmir Tepecik Eğitim ve Araştırma Hastanesi, Çocuk Yoğun Bakım Ünitesi, Izmir, Türkiye \\ * T.C.S.B. Izmir Tepecik Eğitim ve Araşıtırma Hastanesi, Çocuk Acil Servisi, Izmir, Türkiye \\ ** T.C.S.B. Izmir Tepecik Eğitim ve Araşıırma Hastanesi, Çocuk SağıIğı ve Hastalılkları Klinikleri, Izmir, Türkiye \\ *** T.C.S.B. Izmir Tepecik Eğitim ve Araşstırma Hastanesi, Çocuk Nefrolojisi Kliniği, Izmir, Türkiye
}

\section{Özet}

Amaç: Santral venöz kateter yerleştirilmesi yoğun bakım birimlerinde sık kullanılan bir yöntemdir. Bu çalışmada çocuk yoğun bakım biriminde santral venöz kateter yerleştirilmesi ile ilişkili komplikasyonların ve bu komplikasyonlara yol açabilecek risk etmenlerinin değerlendirilmeleri amaçlanmıştır.

Gereç ve Yöntem: 01.07.2007-01.08.2009 tarihleri arasında İzmir Tepecik Eğitim ve Araştırma Hastanesi Çocuk Sağlığı ve Hastalıkları Klinikleri'nde Tıbbi-Cerrahi Çocuk Yoğun Bakım Birimi'ne yatan ve santral venöz kateter yerleştirilen 110 hasta (ortalama yaş: 46,9 $\pm 54,5$ ay; ortanca yaş: 21 ay; dağılım 228 ay-1 ay: 49 kız /61 erkek) çalışmaya alındı.

Bulgular: Tüm olgulara toplam 128 [88 $(\% 68,8)$ femoral, $37(\% 28,9)$ subklaviyen ve üç $(\% 2,3)$ juguler] kateter yerleştirilmişdi. Kateter yerleştirilmesi sırasında altı komplikasyon $(\% 4,7)$, izlem sırasında ise 12 enfeksiyon $(\% 9,4)$, altı tromboz $(\% 4,7)$ ve iki $(\% 1,6)$ kaza ile yerinden çıkma görülmüştür. Kateter yerleştirme işlemi sırasında görülen komplikasyonlarla ilişkili herhangi bir risk etmenine rastlanmamıştır ( $p>0,05)$. Femoral ve subklaviyen kateter yerleştirilen olgular arasında komplikasyonlar açısından bir fark bulunmamıştır $(p>0,05)$.

Çıkarımlar: Çocuk yoğun bakım birimlerinde santral venöz kateter yerleştirilmesi deneyimli ellerde güvenilir bir işlemdir. (Türk Ped Arş 2011; 46: 215-9)

Anahtar sözcükler: Çocuk yoğun bakım birimi, komplikasyon, santral venöz kateterizasyon

\section{Summary}

Aim: Central venous catheter insertion is a procedure commonly used in intensive care units. In this study, the evaluation of complications related to central venous catheterisation inserted in the pediatric intensive care unit and the risk factors associated with complications of central venous catheters are intended.

Material and Method: Between 07.01.2007-08.01.2009, in Izmir Training and Research Hospital, Clinics of Pediatrics, Pediatric Medical-Surgical Intensive Care Unit, 110 patients with central venous catheters (mean age: $46.9 \pm 54.5$ months, median age: 21 months, range 1 month-228 months: 49 female / 61 males) were studied.

Results: A total of 128 catheters [femoral, subslavian and jugular catheters as 88 (68.8\%), $37(28.9 \%)$ and three (2.3\%), respectively] were inserted in 110 patients. During catheter insertion, six insertion-related complications (4.7\%) occured whereas 12 infections (9.4\%), six thromboses (4.7\%) and two (1.6\%) accidental removals were observed during follow-up. No risk factors were observed for catheter insertion-related complications ( $p>0.05)$. There was no significant difference in the risk of complications observed between the cases with subklavian and those with femoral catheterization ( $p>0.05)$.

Conclusions: The placement of central venous catheters in pediatric intensive care unit is a safe procedure in experienced hands. (Turk Arch Ped 2011; 46: 215-9)

Key words: Central venous catheterization, complication, pediatric intensive care unit.

Yazışma Adresi/Address for Correspondence: Dr. Ayşe Berna Anıl, T.C.S.B. İzmir Tepecik Eğitim ve Araştırma Hastanesi,

Çocuk Yoğun Bakım Ünitesi, İzmir, Türkiye E-posta: aysebernaanil@hotmail.com Geliş Tarihi/Received: 26.01.2011 Kabul Tarihi/Accepted: 31.03.2011

Türk Pediatri Arşivi Dergisi, Galenos Yayınevi tarafindan basılmıştır. / Turkish Archives of Pediatrics, published by Galenos Publishing 


\section{Giriş}

Santral venöz kateter (SVK) uygulaması, girișimsel hemodinamik izlem, ilaç ve sıvı uygulamaları, kan alma, hemodiyaliz ve plazmaferez gibi işlemlerin yapılabilmesi için yaygın olarak kullanılan bir yöntemdir. Deriden girerek SVK yerleștirilmesi yoğun bakım birimlerinde sık yapılan girişimlerdir. Çocuk hastalarda SVK yerleştirilmesi için en sık tercih edilen üç bölge femoral, subklaviyen ve internal juguler venlerdir. Özellikle çocuk hastalarda SVK yerleştirilmesinde teknik zorluklar ve komplikasyonlarla daha sık karşılaşılmaktadır. Komplikasyonlar mekanik, trombotik ve enfeksiyöz olmak üzere üç grupta incelenmektedir. Girişimi yapan kişinin deneyimi, kateterin uygulanma bölgesi ve çeşitli risk etmenleri bu komplikasyonların sayı ve şiddetinde etkili olmaktadır $(1,2)$.

Bu çalışmada Çocuk Yoğun Bakım Birimimizde çeşitli nedenlerle SVK yerleştirilen hastalarımızda karşılaşılan komplikasyonların ve ilişkili risk etmenlerinin değerlendirilmesi amaçlanmıştır.

\section{Gereç ve Yöntem}

Sağlık Bakanlığı İzmir Tepecik Eğitim ve Araştırma Hastanesi Çocuk Sağlığı ve Hastalıkları Klinik'leri dokuz yataklı Tıbbi-Cerrahi Çocuk Yoğun Bakım Birimi'nde 01.07.200701.08.2009 tarihleri arasında yatan ve çeşitli nedenlerle (girişimsel hemodinamik izlem, sıvı ve ilaçların enfüzyonu, total parenteral beslenme, vb.) SVK yerleştirilen 110 hastanın kayıtları geriye dönük olarak incelendi. Çalışmada SVK uygulama yeri, kateter kalış süresi ve komplikasyonlar değerlendirildi. Kateter girişimi için trombosit sayısının $>50000 / \mathrm{mm}^{3}$, protrombin ve parsiyel tromboplastin zamanı değerlerinin normal sınılarda olması șartı arandı, bunun sağlanmadığı durumlarda gerekli kan ürünü desteği verildi. Subklaviyen ve juguler kateterlerin tamamı ile girişimin tehlikeli olduğu düşünülen femoral kateterler Çocuk Yoğun Bakım sorumlu uzmanı tarafından, diğer femoral kateterler ise uzman gözetiminde yoğun bakım biriminde eğitim almış kıdemli bir çocuk sağlığı ve hastalıkları araştırma görevlisi tarafından Seldinger tekniği ile yerleştirildi. Tüm hastalara işlem öncesi sedasyon ( $0,1 \mathrm{mg} / \mathrm{kg}$ intravenöz midazolam) ve analjezi $(1 \mu \mathrm{g} / \mathrm{kg}$ intravenöz fentanil) uygulandı. Gerektiğinde nöromüsküler blokan ajan $(0,1 \mathrm{mg} / \mathrm{kg}$ intravenöz vecuronium) da kullanıldı. Girişim sırasında hastalar sürekli olarak kalp hızı ve ritmi, solunum hızı ve oksijen doygunluğu açısından izlendi. Kateterizasyon için subklaviyen, femoral veya internal juguler ven tercihi uygulayıcıya bırakıldı. Ancak, kanama diyatezi olan hastalarda subklaviyen ven girişimi tercih edilmedi. Vücut ağırlığı 5 kg'ın altındakilere 4 Fr, 5-20 kg arasındakilere 5 Fr, 20 kg'ın üzerindekilere ise $7 \mathrm{Fr}$ boyutunda iki lümenli geçici kateter (Poliüretan, Braun Melsungen, Melsungen, Germany) yerleștirildi. İşlem öncesi uygun el yıkama ve aseptik koşullar sağlandı. Kateter yerleştirilecek bölgenin sterilizasyonu \%10'luk povidon iyot ile yapıldı. İşlem sonrasında direkt grafi çekilerek kateterin ucunun subklaviyen ve juguler kateterlerde vena kava süperior ile sağ atriyum arasında, femoral kateterlerde ise vena kava inferiyorda olduğu doğrulandı. Tüm kateter lümenlerinin günlük kan akımı kontrolü yapıldı. Kateter tıkanmasından korunmak için sürekli uygun sıvı infüzyonu uygulandı. Hiçbir hastada sürekli heparinizasyon uygulaması yapılmadı.
Kan akımı enfeksiyonu olmadan kateter çıkış yerinin $2 \mathrm{~cm}$ çevresinde eritem ve endürasyon olması kateter çıkış yeri enfeksiyonu olarak belirtildi. Kateterden alınan kan kültürü ile periferik kan kültüründe aynı mikroorganizmanın üremesi yanında sepsis klinik bulgu ve belirtilerinin de (ateş, hipotermi, lökositoz, taşikardi, metabolik asidoz,vb.) olması kateter ilişkili kan akımı enfeksiyonu olarak tanımlandı (3).

Tüm olguların ölüm riskleri PIM II (Çocuk ölüm indeksi II) (http://www.sfar.org/scores2/pim22.php) ve PRISM (Çocuk ölüm riski) (http://www.sfar.org/scores2/prism2.php) modelleri ile öngörüldü. Ölüm oranı risk hesaplamaları internet ortamında yapıldı.

İstatistiksel analizde SPSS 13.0 paket programı kullanıldı. Değerlendirmede sayısal veriler ortalama \pm standart sapma, ortanca (medyan), dağılım aralığı (en küçük-en büyük), kategorik veriler ise yüzde (\%) olarak belirtildi. Normal dağılım gösteren sayısal veriler Student-t testi ile, normal dağılım göstermeyen sayısal veriler Mann-Whitney $U$ testi ile ve kategorik veriler ki-kare testi ile değerlendirildi. $p<0,05$ istatistiksel olarak anlamlı kabul edildi.

\section{Bulgular}

Bu çalıșmada 49'u kız (\%44,5), 61'i erkek (\%55,5) toplam 110 hastaya 128 SVK (93 hastaya 1, 16 hastaya 2, 1 hastaya 3 kateter) yerleştirildi. Hastaların ortalama yaşı $46,9 \pm 54,5$ ay (ortanca yaş 21 ay; en küçük 1 ay- en büyük 228 ay) olup, yatış süresi ise ortalama 25,4 $\pm 32,3$ gündür (ortanca 14 gün; en az 1 gün - en çok 160 gün). Olguların ortalama PiM ve PRiSM ölçekleri kullanılarak elde edilen değerler sırasıyla $34,8 \pm 32,7$ (ortanca 20,6; en düşük 0,3-en yüksek 100) ve 33,6 $\pm 32,1$ (ortanca 19,2; en düşük 0,7-en yüksek 100) olarak hesaplandı.

Kateter kalış süresi ortalama 10,2 7,5 gün (ortanca: 8 gün; en az 1 gün-en çok 33 gün) olarak gerçekleşti. Olguların 55 'inde (\% 50) altta yatan süreğen bir hastalık, 21 'inde (\%19) ise malnütrisyon saptandı. İzlem süresi içinde toplam 40 hasta $(\% 36,4)$ öldü. Olguların yoğun bakıma giriş tanıları değerlendirildiğinde en geniş grubu sepsis (33 olgu), akciğer hastalığı (30 olgu) ve travma (12 olgu) oluşturdu (Tablo 1).

Olguların 88'ine $(\% 68,8)$ femoral, 37'sine subklaviyen (\%28,9), üçüne juguler $(\% 2,3)$ kateter yerleştirildi. En sık vücudun sağ tarafı $(100$ adet; \%83,3) kullanıldı.

\section{Tablo 1. Olguların yoğun bakıma giriș tanıları}

\begin{tabular}{|l|c|c|}
\hline Yoğun bakım giriş tanısı & $\mathbf{n}$ & $\%$ \\
\hline Sepsis & 33 & 30,0 \\
\hline Akciğer hastalığı & 30 & 27,3 \\
\hline Travma & 12 & 11,0 \\
\hline Nörolojik hastalık & 9 & 8,2 \\
\hline Hemato-onkolojik hastalık & 7 & 6,4 \\
\hline Kalp ve damar sistem hastalı̆̆ı & 5 & 4,5 \\
\hline Zehirlenme & 4 & 3,6 \\
\hline Sindirim sistemi hastalığı & 3 & 2,7 \\
\hline Genitoüriner sistem hastalı̆̆ı & 2 & 1,8 \\
\hline Diğer & 5 & 4,5 \\
\hline Toplam & 110 & 100 \\
\hline
\end{tabular}


Tablo 2. Kateter yerleştirilmesi sırasında gelişen komplikasyonlarda risk etmenleri

\begin{tabular}{|l|c|c|c|}
\hline & Komplikasyon (+) $\mathbf{n : 6}$ & Komplikasyon (-) n:122 & $\mathbf{p}$ \\
\hline $\begin{array}{l}\text { Cinsiyet } \\
\text { Kız (\%) }\end{array}$ & $4(66,7)$ & $45(36,9)$ & 0,054 \\
\hline Erkek (\%) & $2(33,3)$ & $77(63,1)$ & 0,054 \\
\hline Altta yatan hastalık varlığı (\%) & $1(16,6)$ & $51(41,8)$ & 0,079 \\
\hline Malnütrisyon varlığı (\%) & $1(16,6)$ & $21(17,2)$ & 0,388 \\
\hline Yaş (ay, ortanca) & 55 & 21 & 0,319 \\
\hline
\end{tabular}

Tablo 3. Subklaviyen ve femoral kateter gruplarının karşılaştırılması

\begin{tabular}{|l|c|c|c|}
\hline & Subklaviyen kateter $\mathbf{n = 3 7}$ & Femoral kateter $\mathbf{n = 8 8}$ & $\mathbf{p}$ \\
\hline Süreğen hastalık (\%) & $16(43,2)$ & $43(\% 48,8)$ & 0,566 \\
\hline Malnütrisyon (\%) & $6(16,2)$ & $15(\% 17,4)$ & 0,982 \\
\hline Cinsiyet, Erkek(\%) & $17(45,9)$ & $31(\% 35,2)$ & 0,160 \\
\hline Ortalama hasta yaşı (ay) & $52,4 \pm 71,1$ & $45,2 \pm 47,3$ & 0,544 \\
\hline PiM skoru (ort \pm SD) & $36,5 \pm 36,4$ & $34,7 \pm 31,5$ & 0,796 \\
\hline PRisM skoru (ort \pm SD) & $38,0 \pm 31,8$ & $32,2 \pm 32,5$ & 0,411 \\
\hline
\end{tabular}

Tablo 4. Kateter yeri ile komplikasyon gelişimi arasındaki ilişki

\begin{tabular}{|l|c|c|c|}
\hline Komplikasyon & Subklaviyen kateter $\mathbf{n = 3 7}$ & Femoral kateter $\mathbf{n = 8 8}$ & $\mathbf{p}$ \\
\hline Kateter kalış süresi, gün (ortanca) & 7,5 & $\mathbf{1 0}$ & 0,62 \\
\hline Kateter yerleştirilmesi sırasında komplikasyon, $\mathrm{n}(\%)$ & $1(2,7)$ & $2(2,3)$ & 0,624 \\
\hline Kaza ile yerinden çıkma, $\mathrm{n}(\%)$ & 0 & $3(3,4)$ & 0,447 \\
\hline Kateter çıkıs yeri enfeksiyonu, $\mathrm{n}(\%)$ & $2(5,4)$ & $4(4,5)$ & 0,603 \\
\hline Kateter ilişkili kan akımı enfeksiyonu, $\mathrm{n}(\%)$ & $3(8,1)$ & $6(6,8)$ & 0,429 \\
\hline Tromboz, $\mathrm{n}(\%)$ & 0 & $10(11,4)$ & 0,103 \\
\hline Komplikasyon nedeniyle kateterin çıkarıması, $\mathrm{n}(\%)$ & $3(8,1)$ & 0,586 \\
\hline
\end{tabular}

Kateterlerin 88'i $(\% 68,8)$ şok nedeniyle uygun sıvı ve tıbbi tedavi, 40'ı (\%31,2) ise beslenme desteği sağlamak amacıyla yerleştirildi. Kateterlerin 73'ü (\%57) gereksinim ortadan kalktığından, 13'ü $(\% 10,1)$ ise komplikasyon geliştiğinden çıkarıldı.

Kateter yerleştirilmesi sırasında altı $(\% 4,7)$ komplikasyon gelişti (iki arter ponksiyonu, iki hematom, bir aritmi, bir pnömotoraks). Pnömotoraks subklaviyen ven girişimi sırasında, diğerleri ise femoral ven girişimi sırasında ortaya çıktı.

Kateter izlemi sırasında $20(\% 15,6)$ komplikasyon gelişti (yedi kateter ilişkili kan akımı enfeksiyonu, beş kateter çıkış yeri enfeksiyonu, altı tromboz, iki kaza ile yerinden çıkma). Tromboz ve enfeksiyon komplikasyonlarının tümü bir haftadan daha uzun süreli kateterizasyonlarda görüldü.

Kateter yerleştirilmesi sırasında gelişen komplikasyonlar ile ilişkili risk etmenlerinin analizi Tablo 2'de gösterildi. Bu analizlerin hiçbirinde gruplar arasında istatistiksel olarak anlamlı fark saptanmadı ( $p>0,05)$.

Femoral ve subklaviyen kateter yerleştirilen olguların özellikleri arasında istatistiksel olarak anlamlı bir fark saptanmadı ( $p$ $>0,05$ ) (Tablo 3). Juguler ven kateterizasyonu sadece üç olguda yapıldığından, bu grupla ilgili bir değerlendirme yapılmadı.

Femoral ve subklaviyen kateter yerleştirilen gruplar arasında komplikasyon gelişimi açısından da anlamlı bir fark bulunmadı ( $p>0,05)$ (Tablo 4).

\section{Tartışma}

Santral venöz kateter uygulaması kritik hasta yönetiminde önemli bir rol oynamaktadır. Bu yöntemle girişimsel hemodinamik izlem, plazmaferez ve hemodiyaliz gibi ekstrakorporeal tedavilerin yapılabilmesi yanında, ilaç tedavileri için uygun bir damar yolu da sağlanabilmektedir. Perkütan yolla SVK yerleştirilmesi yoğun bakım birimlerinde sık yapılan girişimlerdir $(1,2)$. Ancak Türkiye'de çocuk yoğun bakım birimlerinde SVK girişimlerinin ve komplikasyonlarının değerlendirildiği klinik araştırmalar PubMed tıbbi bilgi erişim tabanında (www.ncbi.nlm.nih.gov/pubmed) çok sınırlı olup $(1,2)$, Türkiye Atıf Dizini'nde (www.atifdizini.com) ise bu konuda bir yayına rastlanılmamıştır. Bu nedenle Çocuk Yoğun Bakım Birimi'mizdeki SVK girişimleri ve komplikasyonları ile ilgili deneyimlerimizi paylaşmanın Türkiye verilerine katkı sağlayacağını düşünmekteyiz.

Erişkinlerle kıyaslandığında çocuklarda perkütan SVK yerleştirilmesi teknik olarak daha zor ve tehlikelidir $(4,5)$. Çalışmamızda, tüm kateter yerleştirme girişimleri başarıyla (\%100) sonuçlanmıştır. Sadece iki olguda kateter yerleştirme sırasında hematom geliştiğinden kateter yerinin değiştirilmesine gerek duyulmuştur. Bu başarılı sonuçta tüm kateter girişimlerinin uygun koşullarda yapılmış olması yanında, subklaviyen kateterlerin hepsinin ve tehlikeli görülen femoral kate- 
terlerin çocuk yoğun bakım uzmanı, diğerlerinin ise uzmanın gözetiminde kıdemli asistan tarafından yerleştirilmesinin önemli rol oynadığını düşünmekteyiz. Yapılan çalışmalar kateter yerleştirilmesi sırasında başarı ve komplikasyon oranlarının hastanın yaşı, ağırlığı, işlemin acil veya uygun olması ve doktorun deneyimi ile ilişkili olduğunu göstermiştir $(6,7)$. Bazı çalışmalar ise kateter yerleştirilmesi sırasında gelişen komplikasyonların yaş ve ağırlık ile ilgili olmadığını belirtmektedir (8-10). Çalışmamızda da kateter yerleştirilmesi sırasında gelişen komplikasyonlarla yaş ve malnütrisyon varlığı arasında bir ilişki saptanmamıştır.

Çalışmamızda 128 kateter yerleştirilmesi sırasında ikisi hematom, ikisi arteriyel ponksiyon, biri aritmi ve biri pnömotoraks olmak üzere toplam altı komplikasyon $(\% 4,7)$ gelişmiştir. Literatürde bu oran \%0,3-22 arasında değişmektedir (11-14). Cerrahi girişim gerektiren erken komplikasyonlar literatürde \%2-3 arasında belirtilirken $(15,16)$, Rey ve ark. (8) bu oranı $\% 0,5$ olarak bildirmiştir. Bizim çalışmamızda ise cerrahi girişim gerektiren bir komplikasyon görülmemiştir. Çalışmamızda sadece bir olguda görülen aritmi ciddi komplikasyon $(\% 0,8)$ olarak kabul edilmiş olup, bu aritmi tablosu da kılavuz telin geri çekilmesi ile kısa sürede düzelmiştir. Kateter yerleştirilmesi sırasında komplikasyon oranımızın düşük olması, ekibin deneyimi yanında tüm hastaların mekanik ventilatörde olmaları ve uygun sedasyon ve analjezi almalarına bağlanmıştır.

Kateter yerleştirilmesi sırasında seçilecek her bölgenin yarar ve engelleri vardır (2). Bazı yazarlar, özellikle kolonizasyon ve enfeksiyon oranı daha düşük olduğundan, subklaviyen ven kateterizasyonunun uzun süreli kateterizasyon için uygun olduğunu belirtmektedir $(17,18)$. Bazı yazarlar ise anatomik olarak kolay ulaşımı, femoral arter nabzının kılavuz olması, arteriyel yaralanma olsa bile hemostazın kolay sağlanabilmesi, femoral ven girişiminin kardiyopulmoner canlandırma için engel teşkil etmemesi, hemotoraks ve pnömotoraks tehlikesi olmaması gibi nedenlerle femoral ven kateterizasyonunu önermektedir $(19,20)$. Bizim çalışmamızda da daha kolay ve çabuk yerleştirilebileceğini düşündüğümüz femoral yol öncelikle $(\% 68,8)$ tercih edilmiştir.

Literatürde olasılıkla teknik zorluk nedeniyle subklaviyen ve juguler venöz kateterizasyon sırasında femoral vene göre daha yüksek oranda komplikasyon bildirilmektedir (21-23). Çalışmamızda ise istatistiksel olarak anlamlı fark olmamakla beraber kateter yerleştirilmesi sırasında görülen altı komplikasyonun beşi femoral kateterizasyon sırasında görülmüştür. Bu durumun subklaviyen girişim sayısının az olması, subklaviyen girişimlerin hepsinin deneyimli uzman tarafından uygun koşullarda yapılmış olması, mekanik ventilatörde derin sedasyon ve analjezi altında teknik zorluk farkının azaltılmış olması ile açıklanabileceğini düşünmekteyiz.

Kateter yerleştirilmesi sırasında görülen komplikasyonlar arteriyel ponksiyon, hematom, aritmi, yanlış yerleştirme, pnömotoraks ve hemotorakstır $(2,5,8)$. Literatürde kateter yerleştirilmesi sırasında arteriyel ponksiyon oranı \%1,9-12,8, hematom görülme oranı ise \%1,4-5,2 arasında değişmekte$\operatorname{dir}(1,2,8,10,13)$. Bizim çalışmamızda arteriyel ponksiyon ve hematom aynı sıklıkta $(\% 1,5)$ ve hepsi femoral girişim sırasında görülmüştür. Gerek arteriyel ponksiyon sonrası görülen kanama, gerekse hematom, bası uygulaması ile kolayca kontrol edilebilmiştir.
Kateter yerleştirilmesi sırasında aritmi gelişmesi bir çalışmada \%0,3, diğer bir çalışmada ise \%2,3 oranında ve daha çok subklaviyen girişim sırasında bildirilmektedir $(8,13)$. Çalışmamızda ise bir hastada $(\% 0,8)$ femoral kateter yerleştirilmesi sırasında aritmi gelişmiştir. Bu durumun hasta yaşının küçük olması (3 aylık) ve kılavuz telin fazla itilmesine bağlı olduğu düşünülmüştür. Subklaviyen kateter yerleştirilmesi sırasında hiçbir hastamızda aritmi görülmemiştir.

Subklaviyen venöz kateter yerleştirilmesi sırasında en sık ve en ciddi komplikasyon pnömotoraks olarak bildirilmektedir. Sıklığı çeşitli çalışmalarda \%1,2-6 arasında değişmekte ve genellikle girişim gerektirmemektedir. Sıklıkla sağ taraftan yapılan girişimlerde görülmekte ve nadiren işlemden 12-24 saat sonra hatta 10 gün sonra bile gelişebilmektedir $(2,5,24-$ 26). Çalışmamızda sadece bir hastada subklaviyen kateter yerleştirilmesi sonrasında pnömotoraks gelişmiştir. Hasta bulgu ve belirti vermediği için herhangi bir girişim yapılmamış ve iki gün sonra düzelmiştir.

Çeşitli yayınlarda SVK yerleştirilen hastaların izleminde görülen komplikasyon oranı \%7-42 arasında değişmektedir $(1,6,13,27)$. Bizim çalışmamızda da bu oran \%15,6 (tromboz, enfeksiyon, kaza ile yerinden çıkma) olarak bulunmuştur. Bu komplikasyonlardan sepsis ve tromboz gelişimi kateterin çıkarılmasını gerektirmektedir (13). İzlemde tromboz ve kateter ilişkili kan akımı enfeksiyonu saptanan 13 olgumuzun da kateterleri çıkarılmıştır. Çalışmamızda sadece iki femoral venöz kateter izlemde kaza ile çıkmıştır. Bu oran literatürdeki diğer çalışmalarda daha yüksek oranlarda $(\% 3,8-13,6)$ bildirilmiştir $(1,10,13)$.

Çalışmalarda, bir haftadan daha uzun süre kalan kateterlerde ultrasonografiyle kateter ilişkili tromboz saptanma oranının \%33-67 arasında değiştiği bildirilmektedir $(28,29)$. Karapınar ve ark. (1) SVK yerleştirilen olgularda bu oranı $\% 2,1$, Casado-Flores ve ark. (13) ise \%2,7 olarak bildirmişlerdir. Araştırmacılar, bu farkın sadece belirti veren olgularda tanısal testler yapmalarından kaynaklandığını belirtmişlerdir. Bizim çalışmamızda da sadece belirti veren olgularda Doppler ultrasonografi yapılmış olup, tromboz \%4,6 oranında saptanmıştır. Femoral katetere bağlı tromboz sıklığı ise subklaviyen ve internal juguler kateterizasyona göre daha yüksek oranda bildirilmektedir $(13,30)$. Çalışmamızda da altı tromboz olgusunun hepsi femoral venöz kateter yerleştirilen hastalarda görülmüştür. Femoral kateterin kalış süresi uzadıkça tromboz tehlikesi arttığından, femoral yolun kısa süreli kateterizasyonlar için tercih edilmesi gerektiği özellikle vurgulanmaktadır (1). Bizim de katetere bağlı tromboz olgularımızın tamamı birinci haftadan sonra görülmüştür. Tromboz gelişen olgularımızda başka bir risk etmeni de saptanmamıştır. Bazı yazarlar beş günden daha uzun süren femoral kateterizasyonda haftada iki kez ultrasonografi eşliğinde tromboz açısından izlem yapılmasının komplikasyon gelişimini önlemede etkin bir yöntem olacağını bildirmektedirler (31,32).

Kateter ilişkili kan akımı enfeksiyonu çalışmamızda \%5,5 oranında saptanmıştır. Bu oran literatürde farklı tanımlama ölçütleri kullanılmasından dolayı \%3,7-40 arasında değişmektedir (6,33). Yayınlarda kateter ilişkili enfeksiyonlarda daha çok koagülaz negatif stafilokoklar bildirilmekte ve kateterizasyon süresi uzadıkça enfeksiyon tehlikesinin arttığı belirtilmektedir $(2,13)$. Literatürden farklı olarak çalışmamızda kateter ilişkili kan akımı enfeksiyonlarında daha çok gram 
negatif basiller saptanmıştır. Çalışmamızda da kateterizasyon süresi uzadıkça enfeksiyon sıklığının artığı görülmüştür. Literatürle benzer şekilde femoral ve subklaviyen bölge arasında kateter ilişkili kan akımı enfeksiyonu gelişimi açısından fark saptanmamıştır $(6,13,20)$.

Sonuç olarak, çocuk yoğun bakım birimlerindeki kritik hasta çocukların izlem ve tedavilerinde gerekli olan SVK uygulaması deneyimli ellerde komplikasyon oranı düşük ve kolay bir girişimdir. Ancak, girişimin yapılacağı damar tercihinde hastanın klinik özellikleri ile hekimin o damara yönelik girişim deneyimi dikkate alınmalıdır.

\section{Çıkar çatışması: Bildirilmedi.}

\section{Kaynaklar}

1. Karapınar B, Cura A. Complications of central venous catheterization in critically ill children. Pediatr Int 2007; 49: 593-9.

2. Çıtak $A$, Karaböcüoğlu $M$, Üçsel $R$, et al. Central venous catheters in pediatric patients - subclavian venous approach as the first choice. Pediatr Int 2002; 44: 83-6.

3. Randolph AG, Brun-Buisson C, Goldmann D. Identification of central venous catheter-related infections in infants and children. Pediatr Crit Care Med 2005; 6: 19-24.

4. Fernandez GF, Sweeney MF, Gren TP. Central venous catheters. In: Dieckman RA, Fiser DH, Selbst SE, (eds). Pediatric emergency critical care procedures. St Louis: Mosby 1997; 196-202.

5. Vane DW, Ong B, Rescorla FJ, et al. Complications of central venous access in children. Pediatr Surg Int 1990; 5: 174-8.

6. Venkataraman ST, Thompson AE, Orr RA. Femoral vascular catheterization in critically ill infants and children. Clin Pediatr 1997; 36: 311-9.

7. Crowley JJ, Pereira JK, Harris LS, et al. Peripherally inserted central catheters: experience in 523 children. Radiology 1997; 204: 617-21.

8. Rey C, Alvarez F, De La Rua V, et al. Mechanical complications during central venous cannulations in pediatric patients. Intensive Care Med 2009; 35: 1438-43.

9. Garsia-Teresa MA, Casado-Flores J, Dominguez MAD, et al. Infectious complications of percutaneous central venous catheterization in pediatric patients. Intensive Care Med 2007; 33: 466-76.

10. Cruzeiro PC, Camargos PA, Miranda ME. Central venous catheter placement in children: a prospective study of complications in Brazilian public hospital. Pediatr Surg Int 2006; 22: 536-40.

11. Johnson EM, Saltzman DA, Suh G, et al. Complications and risks of central venous catheter placement in children. Surgery 1998; 124: 911-6.

12. Casado-Flores J, Barja J, Martino R, et al. Complications of central venous catheterization in critically ill children. Pediatr Crit Care Med 2001; 2: 57-62.

13. Sheridan RL, Weber JM. Mechanical and infectious complications of central venous cannulation in children: lessons learned from a 10-year experience placing more than 1000 catheters. J Burn Care Res 2006; 27: 713-8.
14. Alvarado-Diez MA, Marquez-Enriquez LM, Troconis-Trens G, et al. Experience in the use of central venous catheterization via subclavian puncture in a pediatric hospital. Bol Med Hosp Infant Mex 1993; 50: 394-8.

15. Mansfield PF, Hohn DC, Fornage BD, et al. Complications and failures of subclavian-vein catheterization. N Engl J Med 1994; $331: 1735-8$.

16. Sitzmann JV, Townsend TR, Siler MC, et al. Septic and technical complications of central venous catheterization. A prospective study of 200 consecutive patients. Ann Surg 1985; 202: 766-70.

17. Collignon P, Soni N, Pearson I, et al. Sepsis associated with central vein catheters in critically ill patients. Intensive Care Med 1988; 14: 227-31.

18. Brun-Buisson C, Abrouk F, Legrand P, et al. Diagnosis of central venous catheter related sepsis: critical level of quantitative tip cultures. Arch Intern Med 1987; 147: 873-7.

19. Stenzel JP, Gren TP, Fuhrman BP, et al. Percutaneous femoral venous catheterizations: a prospective study of complications. J Pediatr 1989; 114: 411-5.

20. Kanter RK, Gorton JM, Palmieri K, et al. Anatomy of femoral vessels in infants and guidelines for venous catheterization. Pediatrics 1989; 83: $1020-2$

21. Polderman KH, Girbes AJ. Central venous catheter use. Part I. Mechanical complications. Intensive Care Med 2002; 28: 1-17.

22. Haas NA. Clinical review: vascular access for fluid infusion in children. Crit Care 2004; 8: 478-84.

23. Mallinson C, Bennett J, Hodgson P, et al. Position of the internal jugular vein in children. A study of the anatomy using ultrasonography. Paediatr Anaesth 1999; 9: 111-4.

24. Randolph AG, Deborah JC, Gonzales CA, et al. Ultrasound guidance for placement of central venous catheters: a meta-analysis of the literature. Crit Care Med 1996; 24: 2053-8.

25. Spiliotis J, Kordossis T, Kalfarentzos F. The incidence of delayed pneumothorax as a complication of subclavian vein catheterization. $\mathrm{Br} \mathrm{J}$ Clin Pract 1992; 46: 171-2.

26. Yerdel MA, Karayalçın K, Aras N, et al. Mechanical complications of subclavian vein catheterization. A prospective study. Int Surg 1991; 76 : 18-22.

27. Venkataraman ST, Orr RA, Thompson AE. Percutaneous infraclavicular subclavian vein catheterization in critically ill infants and children. $J$ Pediatr 1988; 113: 480-5.

28. Bernard RW, Stahl WM. Subclavian vein catheterizations: a prospective study. I. Non infectious complications. Ann Surg 1971; 173: 184-90.

29. Randolph AG, Cook DJ, Gonzales CA, et al. Benefit of heparin in central venous and pulmonary artery catheters: a meta-analysis of randomized controlled trials. Chest 1998; 113: 165-71.

30. Gualtieri E, Deppe SA, Sipperly ME, et al. Subclavian venous catheterization: greater success rate for less experienced operators using ultrasound guidance. Crit Care Med 1995; 23: 692-7.

31. Kraffe-Jacobs B, Sivit CJ, Mejia R, et al. Catheter-related thrombosis in critically ill children: comparison of catheters with and without heparin bonding. J Pediatr 1995; 126: 50-4.

32. Sheffler A, Gillis J, Lam A, et al. Inferior vena cava thrombosis as a complication of femoral vein catheterization. Am J Dis Child 1995; 72: 343-5.

33. Pinilla JC, Ross DF, Martin T, et al. Study of the incidence of intravascular catheter infection and associated septicemia in critically ill patients. Crit Care Med 1983; 11: 21-5. 